\title{
A Framework for the Analysis of the Potential Performance of Chief Information Officers
}

\author{
João Varajão ${ }^{1,2}$, Luís Amaral ${ }^{2,3}$, Ricardo Colomo Palacios ${ }^{4}$, and Jorge Gouveia ${ }^{1}$ \\ ${ }^{1}$ University of Trás-os-Montes and Alto Douro, Vila Real, Portugal \\ \{jvarajao, jgouveia\}@utad.pt \\ ${ }^{2}$ Centro ALGORITMI, Guimarães, Portugal \\ ${ }^{3}$ University of Minho, Guimarães, Portugal \\ amaraledsi.uminho.pt \\ ${ }^{4}$ Universidad Carlos III de Madrid, Computer Science Department \\ Av. Universidad 30, Leganés, 28911, Madrid, Spain \\ ricardo.colomo@uc $3 \mathrm{~m}$.es
}

\begin{abstract}
Information Systems Function is an organisational area of major importance in the context of the competitive development of organisations. At the centre of the Information Systems Function we find the Chief Information Officer (CIO), who is the main responsible for the organisation and leadership of this function. Given the nature of the duties assigned to the $\mathrm{CIO}$, her/his work directly influences the development of an organisation, so it has become important to assess her/his potential performance before s/he finds herself/him in charge of the information systems function. This article proposes the CIO Performance Square - a framework for analysing the potential performance of CIOs based on their education and experience.
\end{abstract}

Keywords: CIO, competence, framework, education, experience.

\section{Introduction}

The Information Systems Function (ISF), which can be understood as the set of activities that aims at the optimisation of an information system [1], is nowadays - more than ever - crucial for the success of any organisation, given the importance of information as a pivotal resource for effective management. It is a fact that the capacity to recognize the importance of the management of information for the organizational development was not always widespread in organizations and, on the other hand, it is actually true that there is a growing concern in equipping the companies with adequate information system (IS) to support their business activities. For some years it has been noted that in a large number of activity areas, like, for example, the banking or insurance sectors, an inadequate management of the ISF could result in such grave consequences, as the extinction of an institution [2].

In spite of Information Technologies (IT) being recognised as powerful and indispensable instruments for the survival and evolution of any organization $[3,4]$ the simple adoption of IT does not guarantee the obtaining of positive results or competitive advantages. This is so because there is not a direct relationship between the 
adoption of IT and achieving a satisfactory return, in which the fulfillment degree depends ultimately on the way available technologies are used [5, 6].

Notwithstanding the non-existence correlation between IS and IT and organisations' success, there exists a good correlation between IS success and the way in which it is managed [7, 8]. IS management, while active in combining the management of IT and IS with a dynamic conception of organisation in a determined contextual environment [9], become the main responsible for assuring the correct use of all of the elements and resources of IT in efficiently supporting an organisation's IS [10]. This concern is absolutely necessary, to avoid a mismatch between increases in IT technological capacities and levels of investment, and similar increases in productivity [7, 8].

It is to the IS management, as the main responsible for information resources management and all of the resources involved in the planning, development and exploration of the IS, who competes to equip the organisation with the right systems in order to assure the satisfaction the organization's informational needs [10].

Given the importance of the $\mathrm{CIO}$, as the primary responsible for conduction the ISF, it becomes important to assess her/his performance potential prior to being in charge of this important function [1]. According to [3], the CIO potential to play a critical role in the strategy and change processes of firms is arguably greater today than ever before.

This article presents a framework for analysing the potential performance of CIOs based on her/his education and professional experience. In the following sections after a brief outline about the nature of the systems management activity - we discuss the management of information systems and propose the CIO Performance Square framework.

\section{The Management Activity}

Management is generally described as a process of leadership involving planning, structuring, direction and control functions. These functions are based on the management functions postulated by Henry Fayol - a pioneer in the Theory of Organisations - at the start of the 20th Century. Managers must plan their activities and those of their organisations, organise human resources and their activities, direct and control operations, while assessing their own performance in such a way that they are able to make any necessary readjustments [11].

The role of managers in organisations can be examined essentially at two levels: internally, as an element holding the internal social system that preserves the organisation unity; and, externally, as a representative of the organization in its external environment. They need to define the strategy for attaining the business objectives, whether in a process of continuous negotiation with the stakeholders or in the necessary articulation with the workers, albeit, as part of the true social system that comprises any organisation [12].

Managers also represent organisations in all of their external relationships. Their role is particularly relevant at the tactical level and in interaction with the external environment. Given that they should carefully analyse the markets in which the 
business operates (or potentially would like to move into), aiming to define the performance strategy that, with higher probability, could lead to the obtaining of resources and the placing of the output in the desired conditions, taking into account the dimension of the established specific objectives [12]. As decision-makers, they also should develop negotiating relationships with the markets where the company compete.

The manager is also responsible for negotiations with stakeholders, aiming to obtain the necessary resources to maintain the organisation's activity cycle, so that it can achieve its objectives. At the operational level, her/his field of performance is the optimal combination of resources including informational, material and human. It is the manager's responsibility to define and to manage available resources in order to maximize level of output production at the quality level desired.

One of the crucial roles of a manager is being the leader of the organizational social system. Managers must disseminate the organisation objectives and create the motivation and leadership model that enables the joint compatibility and optimisation of individual and organisational aspects.

There are at least three types of capacities necessary in order for the manager to be able to perform her/his role efficiently; namely [13]:

- Technical capacity: this consists of the aptitude to use knowledge, methods, techniques and necessary equipment to carry out specific tasks and it is obtained by means of instruction, experience and training.

- Human capacity: this consists of the aptitude and discernment for working with people, through an understanding of working with people, of their attitudes and motivations in order to exercise an efficient leadership. Human capacity is intimately related to the capacity of personal inter-relationships and people motivation.

- Conceptual capacity: this consists of the aptitude for understanding the complexities of global organisations and organisations' framework. This capacity allows a person to respond in accordance not only with the objectives and necessities of her/his group, but with the global organisation objectives.

The well-balanced combination of these capacities will vary to an extent according to the holder's hierarchical level, from supervisory positions up to top management. Different levels of management will necessarily require different capacities [14]. As one climbs from the lower levels to higher levels of an organisation, the necessity for technical capacity decreases, while the demand of conceptual competencies increases. At lower levels, supervisors need a considerably higher technical capacity in order to be able to instruct and train technicians and other sub-ordinates. At the highest levels the executives do not need to know the details of specific tasks carried out at the operational level. Although the proportion of technical and conceptual capacities needed at different levels of the organisation varies, the fundamental common denominator at all levels is the human capacity. Nevertheless, all managers perform the same functions - namely, planning, organising, directing and controlling - emphasis applied to each function differs according to the management level in the organisational hierarchy [15]. 


\section{The Management of Information Systems}

Like any management activity, the information systems management (ISM) is in charge of the planning, structuring, direction and control of activities needed in an organisation in order to guarantee the existence of an adequate IS for its informational needs. In other words, it is responsible for the ISF management.

Planning involves the development of action programmes and policies, objectives and strategies formulation, including the perception and analysis of both opportunities and problems. The ISM needs to play a particularly active and direct role in the IS planning, intended as a management task to handle the integration of aspects related with IS in the organisational planning process.

Structuring consists of allocating tasks to individuals and groups, through authority and responsibility delegation. It refers essentially to the way of activities are organized and resources are used. Thus, in the structuring area, resources are distributed, work orders are given out, etc.

Direction is the leadership of the organisation by means of communication and personnel motivation. The ISM is, therefore, responsible for co-ordinating and inspecting work, motivating workers and rewarding or punishing them, resolving conflicts, etc. Here, the human relationship capacity and knowledge of various psychological and sociological variables is fundamental.

Control involves observation and measurement of organisational performance and the surrounding activities, so as to modify plans and activities when necessary. In practice, this translates into budgetary control, control of plans materialization, control of work teams, control of costs, control of invoicing and supply of services or resources, etc.

It is interesting to note the extreme difficulty of delineating the responsibilities of a CIO, due to the inevitable variation of functional aspects like, for example, the size of the organisation (in some cases in small businesses, the ISF "team" will be constituted by a single person - the IS manager - who will be responsible for all the IS activities).

The manager must plan her/his activities and the ISF activities, establish an interface between the other organisational areas and the ISF, manage the global conception of IS, organise resources and activities, direct and control operations, while evaluating her/his own performance in order to make any necessary adjustments.

According to [16], the CIO role as we know emerged in the 1970s, while [17] states that it emerged in the 1950's as a data processing manager, and it has evolved over the years to that of an executive dealing with the use of information communication technology from a social, economic and strategic management viewpoint. One of the characteristics of CIOs is the proximity of this role to the senior management of a company [18]. Typically, the primary focus of the CIO is strategic information systems planning and his/her responsibilities cover a broad technical and organizational scope [19]. Moreover, there is a consensus among researchers about the crossfunctionality of the IT strategy, as it encompasses product, process, and human resources and is intertwined with corporate strategy [20].

The role of the CIO can be regarded from two perspectives: at the internal system and at external relationships. Internally, it is necessary to maintain good relationships not only with her/his co-workers, but also with other organisational areas in order to 
ensure good communication by reaching a balance between users and directed coworkers, enabling the overcoming of differences when these arise. The field of work of a CIO resides in the optimal combination of resources - information, technological, human and financial. With respect to the second perspective, related to relationships with the external environment, there is a need to establish contacts and negotiate relationships with suppliers, partners of the organisation, IS managers of other organisations, amongst others, in order to obtain information, arrange contracts and serve as the representative figure of the organisation. A given CIO is also responsible for analysing markets aiming to define the action strategy that - with a higher possibility may lead to the obtaining of the necessary resources consistent the organisation objectives.

The work of the CIO presents a significant bureaucratic component, which includes building relationships with her/his superior hierarchy, participating in meetings to discuss various general aspects of the organisation, making internal proposals for acquisitions, raising reports about a range of activities for their presentation to higher authorities, making requisitions for specific services (such as physical installations maintenance), developing internal proposals (self-generated or in relation to competitive budgets from external suppliers), carrying out orders from a higher authority, etc.

There also exists an aspect of considerable relevance among the activities of an IS manager, which in practice has been verified many times to be underestimated or even completely ignored: internal marketing.

Internal marketing is materialised through various actions like the dissemination and publication of results and communications to other areas of the organisation about the work carried out by the ISF. For instance, by means of meetings when projects are concluded or conducting enquiries about the functioning of new systems. In case these actions are not carried out, there exists the risk of remembering systems only for the "only one day in which problems occurred in a period of several months of normal operations." Also it is important to develop actions prior to the system implementation identifying which ones require people inside the organisation to be informed and/or prepared for changes that will occur, thereby diminishing any future resistance. In sum, the ISF credibility depends also on the accumulation and publication of the successes attained and also on paying close attention to its users.

Top management often does not have the right perception of the work involved or necessary in each service rendered by the IS area. This can be due to the incapacity of the IS manager to promote an organisational culture that is conscious of the difficulties and complexities of the ISF.

\section{Framework for the Analysis of the Potential Performance of the CIO}

Several research works have examined the CIO's roles, attributes, and capabilities to understand the characteristics of high-performing CIOs back in the nineties [21], [22], [23], [24], [25]) and also in the first decade of 21st century (e.g. [17], [26], [27]). Concerning the $\mathrm{CIO}$ work, it is possible to verify two aspects in practice, which can 
be emphasized as contributing decisively to her/his performance [1]: education and experience. The problem of many present information systems is the inadequate satisfaction of the informational needs of their organizations or the lack of versatility in responding to changes. The problem is the deficiency of business vision of many CIOs, that present a strictly technological vision of the IS, which is a direct consequence of her/his education/training and experience.

Figure 1 below presents a framework for the analysis of the potential performance of a CIO based on her/his education and experience.

EXPERIENCE

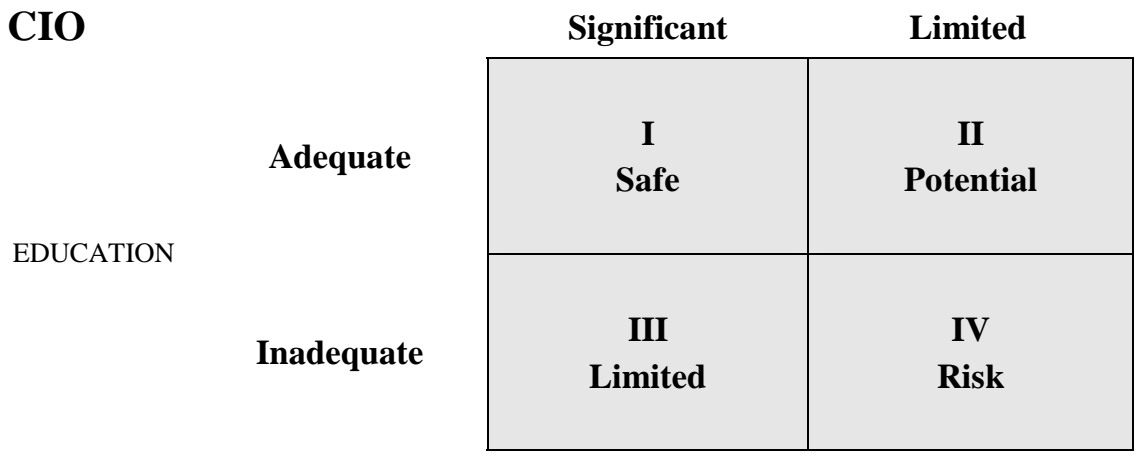

Fig. 1. CIO Performance Square

CIOs who are positioned in Quadrant I, having an adequate education/training and a significant experience, will be able to adequately develop their job with a high degree of certainty (safe), given that they are not only ISF experts but also know their role in the organisation, while also being familiar with the complexities and difficulties of the IS management practice. In the case of CIOs located in Quadrant II, in spite of their limited experience, an adequate education will allow them to overcome many of the problems that will arise during the materialization of their activities, given the comprehensive vision that their education enables. Such managers will have high potential of succeeding in the future. In Quadrant III, despite the significant experience of the manager, the gaps caused by an inadequate education can lead to a limited performance by the ISM. In the case of managers in Quadrant IV, their limitations represented by an inadequate education and a limited experience will put at risk both the ISF and its own organisation.

The CIO needs to have a comprehensive, deep and realistic knowledge of the organisation and of her/his environment and be aware of approaches, methods, techniques and tools of the area. The present position of the IS management - at the highest levels of the organisational hierarchy - demands individuals with an architectural and integrated knowledge of the ISF, who know the multiplicity of technical, human and business aspects necessary to be considered and who is a well informed "buyer" in all the business external relationships. All in all, organizations need CIOs capable of guiding their business on the diversity of options constantly offered and replaced 
by technology. Such is only possible with a strong technical competency, as stated in [28], [29] and a large awareness for organisational issues [1].

Over and above the education and experience of a CIO, there exists yet another aspect that stands out in the success of the ISM due to the impact that it has on his/her performance: the position of the ISF in the organisation hierarchy. How to conveniently position the responsible ISMs in the structure of the organisation was one of the main problems, which presented itself unexpectedly some years ago. Nevertheless, nowadays the reality is much brighter, as one can find CIOs typically at the top hierarchy, principally in the case of larger companies.

\section{Conclusion}

The key to the ISM success is a balanced approach to management, which does not ignore, but encourages innovation, and reinvents itself continually, as a way of adjusting its structure and practices to the multiple modifications taking place in all organisational environments. Thus, the ISM must be able to improve itself on a continuous basis, aiming to maximize the efficiency for the ISF. For such to be possible, it is important that CIOs have an adequate education and significant professional experience in the area. In this paper, a framework is presented for analysing the potential performance of CIOs. The framework proposes a possibility for classifying the background of the CIO as "Safe," "Potential," "Limited" or "Risk" based on respective training and experience. Future works should be centred on two research lines. The first aims at the development of measurement criteria in order to catalogue CIOs performance in a guided and structured manner. The second research line will pursue the implementation of a tool to support the proposed framework.

\section{References}

1. Varajão, J.: Função de Sistemas de Informação: Contributos para a melhoria do sucesso da adopção de tecnologias de informação e desenvolvimento de sistemas de informação nas organizações. PhD thesis: Universidade do Minho (2002)

2. Ward, J.: Principles of Information Systems Management. Routledge, New York (1995)

3. Enns, H.G., Huff, S.L., Golden, B.R.: CIO influence behaviors: the impact of technical background. Information \& Management 40, 467-485 (2003)

4. Bharadwaj, A.S.: A resource-based perspective on information technology capability and firm performance: An empirical investigation. MIS Quarterly 24(1), 169-198 (2000)

5. Li, F.: The Geography of Business Information. Wiley, Chichester (1995)

6. Strassmann, P.A.: The Squandered Computer - Evaluating the Business Alignment of Information Technologies. Information Economics Press (1997)

7. Amaral, L., Varajão, J.: Planeamento de Sistemas de Informação FCA - Editora de Informática (2000)

8. Amaral, L.A.M.: PRAXIS: Um Referencial para o Planeamento de Sistemas de Informação, in Departamento de Informática. Universidade do Minho, Braga (1994)

9. Zorrinho, C.: Gestão da Informação: Condição para Vencer. IAPMEI (1995)

10. Varajão, J., Amaral, L.: Gestão de Sistemas de Informação: Uma Abordagem Arquitectural. Revista da Associação Portuguesa de Sistemas de Informação, APSI (1999) 
11. O’Brien, J.A.: Management Information Systems: A Managerial End User Perspective, Irwin (1993)

12. Sousa, A.: Introdução à Gestão: Uma Abordagem Sistémica. Verbo (1990)

13. Katz, R.L.: Skills of an Effective Administrator. Harvard Business Review 33(1), 33-39 (1955)

14. Chiavenato, I.: Introdução à Teoria Geral da Administração, 3rd edn. McGraw-Hill, New York (1983)

15. Buckley, M.W.: The Structure of Business. Pitman (1990)

16. Gottschalk, P.: Strategic management of IS/IT functions: The role of the CIO in norwegian organisations. International Journal of Information Management 19, 389-399 (1999)

17. Chun, M., Mooney, J.: CIO roles and responsibilities: Twenty-five years of evolution and change. Information \& Management 46(6), 323-334 (2009)

18. CIO Role Survey. CIO Insight Magazine (350 senior American executives) (April 2002)

19. Lindström, A., Johnson, P., Johansson, E., Ekstedt, M., Simonsson, M.: A survey on CIO concerns-do enterprise architecture frameworks support them? Information Systems Frontiers 8(2), 81-90 (2006)

20. Lefebvre, L.A., Mason, R., Lefebvre, E.: The influence prism in SMEs: The power of CEO's perceptions on technology policy and its organizational impacts. Management Science 43(6), 856-878 (1997)

21. Applegate, L.M., Elam, J.J.: New information systems leaders: A changing role in a changing world. MIS Quarterly 16(4), 469-490 (1992)

22. Stephens, C.S., Ledbetter, W.N., Mitra, A., Ford, F.N.: Executive or functional manager? The nature of the CIO's job. MIS Quarterly 16(4), 449-467 (1992)

23. Grover, V., Jeong, S.R.: The chief information officer: A study of managerial roles. Journal of Management Information Systems 10(2), 107-131 (1993)

24. Earl, M.J., Feeny, D.F.: Is your CIO adding value. Sloan Management Review 35, 11-20 (1994)

25. Moad, J.: Wanted: the multithreaded CIO. Datamation 40(8), 34-38 (1994)

26. Smaltz, D.H., Sambamurthy, V., Agarwal, R.: The antecedents of CIO role effectiveness in organizations: An empirical study in the healthcare sector. IEEE Transactions on Engineering Management 53(2), 207-222 (2006)

27. Heart, T., Hanan, M., Pliskin, N.: From Governance to Adaptability: The Mediating Effect of IT Executives' Managerial Capabilities. Information Systems Management 27(1), 4260 (2009)

28. Colomo-Palacios, R., Tovar-Caro, E., García-Crespo, A., Gómez-Berbis, M.J.: Identifying Technical Competences of IT Professionals. The Case of Software Engineers. International Journal of Human Capital and Information Technology Professionals 1(1), 31-43 (2010)

29. Trigo, A., Varajao, J., Barroso, J., Molina-Castillo, F.J., Gonzalvez-Gallego, N.: IT Professionals: An Iberian Snapshot. The Case of Software Engineers. International Journal of Human Capital and Information Technology Professionals 1(1), 61-75 (2010) 